\title{
Study on the Sequence division and correlation of the Kapushaliang Group in the Western Tabei Uplift
}

\author{
Yongfu Liu \& Yungang Ji1, Guifen $\mathrm{Xu}^{* 2}$ \\ 1.The exploration and exploitation academy, Tarim oilfield, Xinjiang, China \\ 2.College of Resources Energy, China University of Geosciences, Beijing, China
}

Keywords: Sequence stratigraphy; Kapushaliang Group; Palaeogeomorphology; Tabei Uplift

\begin{abstract}
Based on the theory of sequence stratigraphy and seismic stratigraphy, with the integral analysis of the seismic, drilling and logging data, the sequence stratigraphy framework of Kapushaliang Group in the western Tabei Uplift is established. A 2nd-order sequence surface and three 3rd-order sequences surfaces was recognized.The Kapushaliang Group was divided into four 3rd-order sequences. The 3rd-order sequence was controlled by palaeogeomorphology.The bottom sequence overlaped from the sag to the Uplift. At the stage of SQ4, the northern and southern sides of the Uplift were linked together. The sedimentary center migrated in different sequence stages.
\end{abstract}

\section{INTRODUCTION}

Tabei Uplift, one of the most hydrocarbon enrichment tectonic units in Tarim Basin, plays an irreplaceable role in oil and gas exploration and development [Zhang Guangya,1994][Zhou Fengying,2001][Sun Longde,2004][An Haiting,2009].That a series of cretaceous-paleogene oil-gas fields were discovered in Yangtage, Yingmaili, Yaha, Tiergen and Yakela indicates that the Cretaceous has a good exploration prospect. Given the fact that the study on sequence stratigraphy of Cretaceous in the northern Uplift is still weak, based on the previous studies, with the integral analysis of single well, three dimensional seismic profile, connecting-well section and combined well-seismic profile, we reclassified the sequence in the Western Tabei Uplift, and the Sequence framework was established in the study area.

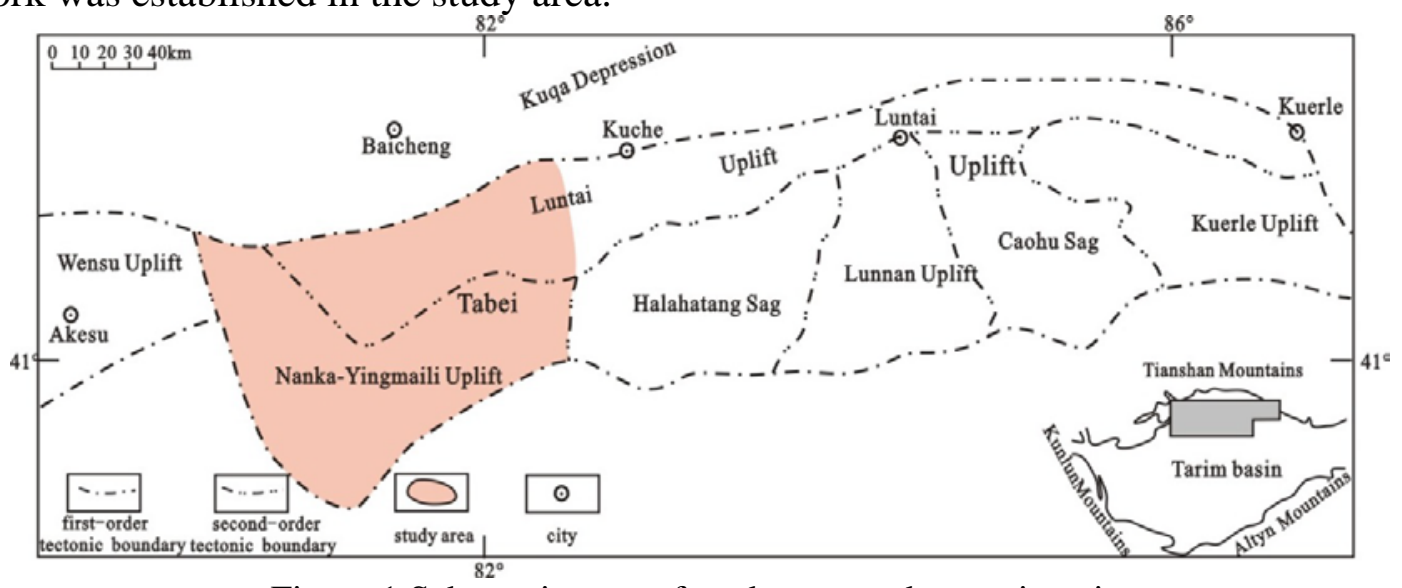

Figure 1.Schematic map of study area and tectonic units

\section{GEOLOGIC SETTING}

Tabei Uplift is an important tectonic unit in Tarim Basin, which is a superimposed palaeouplift developed from Paleozoic to Mesozoic, Awati sag to the west, Kuluketage fault Uplift to the east, kuqa sag to the north and Manjiaer sag to the south (Figure1), and influenced by east-west trending strike-slip fault. In the Yanshanian and early Himalayan, the North-dipping Tabei Uplift tended to be stable [Li Guohui,1994][He Dengfa,2008][An Haiting,2009]and sediments of Jurassic and Cretaceous were overlaped on the Uplift. Then the Tabei Uplift tended to be extinct gradually. The lower Cretaceous, mainly developed in the study area, includes Yageliemu Formati on, Shushanhe 
Formation, Baxigai Formation and Bashijiqike Formation from the bottom to top.The Kapushaliang Group consists of Yageliemu Formation, Shushanhe Formation, Baxigai Formation. As A Whole, the Kapushaliang Group mainly comprises mudstone, siltstone and packsand mainly with oxidation colors but no dark mudstone.

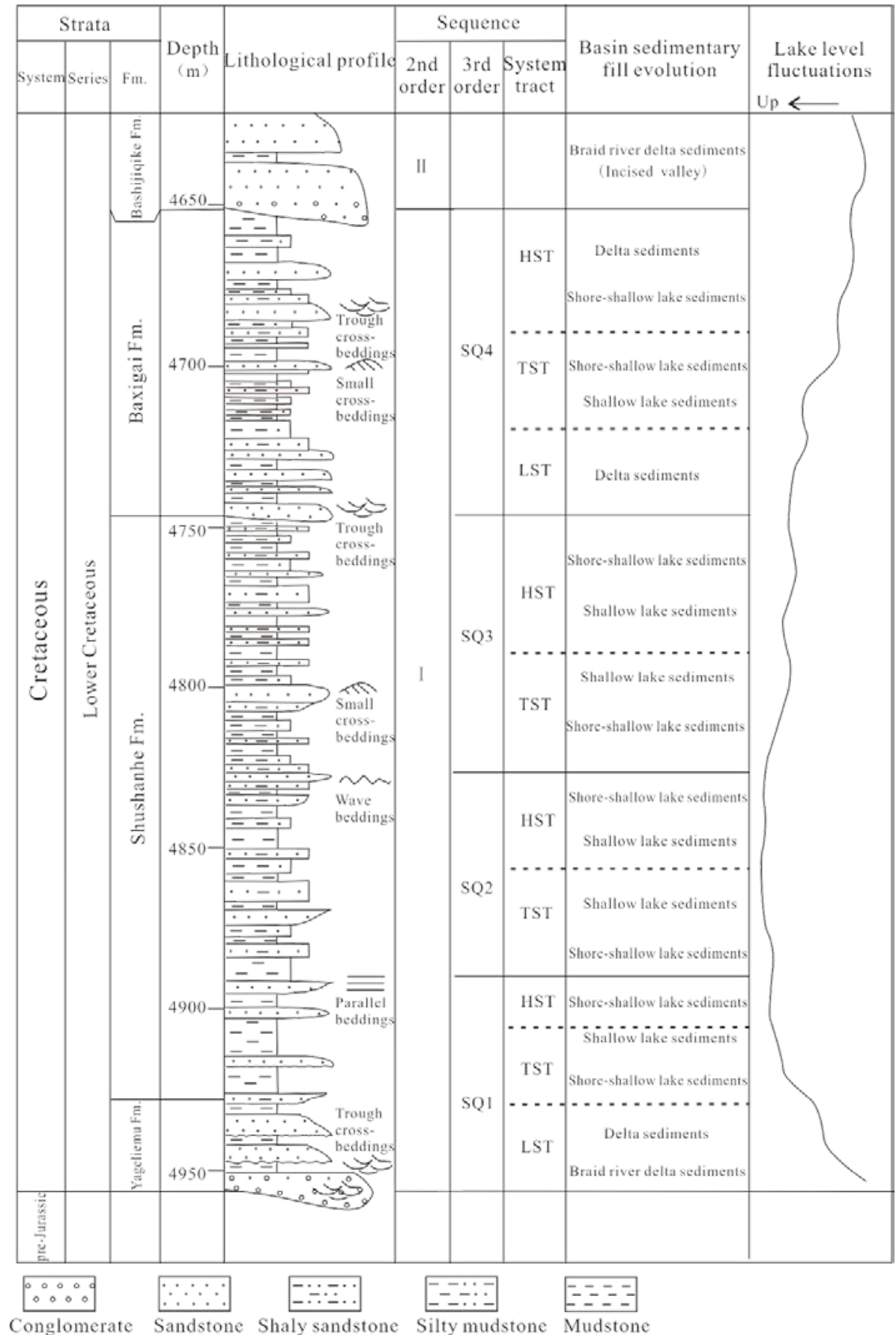

Figure2. Filling succession and sequence units of the Kapushaliang Group in the Tabei Uplift

\section{SEQUENCE DIVISION AND BOUNDARY CHARACTERISTICS}

Depending on the previous research, integrated with seismic data, drilling data and logging data, this study concluded that the sedimentary filling sequences of Kapushaliang Group were a regional 2nd-order eustatic cycle with transgression-regression (Figure2).On the perspective of seismic profiles, the bottom boundary of the sequence (TK), corresponding to T8-2 and under which developing obvious truncation, is a regional unconformity surface and characterized by good continuity as well as moderate strong reflection. In the south of the study area, the Cretaceous has a parallel unconformable contact with the lower Jurassic (Yangxia Fm.). In the middle area, the Cretaceous has a high angle unconformable contact with the underlying Permian, Silurian, 
Ordovician, Lower Cambrian or other old strata, while, a parallel unconformable contact with the Triassic in the north.

Well log data indicates that the Cretaceous has a abrupt contact relationship with the underlying strata, and the sedimentary environment changes obviously. Meanwhile, the GR, SP and resistivity curve all show a mutation. The top boundary TK1bs (T8-2) is the boundary between the Kapushaliang group and Bashijiqike formation. It shows Low frequency and high amplitude, continuous reflection in seismic profile. The seismic reflection strength in upper and lower interface shows great difference, and truncation termination can be identified under the interface locally. Simultaneously erosion unconformity and channel-filling can be found above the interface. This boundary is easy to be tracked in the district (Fig. 3). when it comes to the core, the Bashijiqike formation is characterized with beige sandstone and conglomeratic sandstone, while the underlying Baxigai group is meanly composed of Brown mudstone, light brown sandstone, showing a significant difference in lithology.

The 3rd-order sequence boundary is mainly under the control of the lake level changes and the change of sediment supply rate. On the edge of the basin and Uplift slope area develops the unconformity, but conformity often in the basin. This 3rd sequence boundary can be found in the breaking point position of the strata superposed style. According to this principle, 4 3rd-order sequences can be identified in the Kapushaliang formation. SQ1, SQ2, SQ3 and SQ4 are entitled in turn from bottom to top. Two basic forms of three-order sequence boundary can be identified within the research area. (1)In the Yageliemu and Baxigai group, the 3rd-order sequence boundary shows locally unconformity or erosion surface and its corrsesponding conformity boundary. Incised valleys or channel-filling can be found above the boundary. The 3rd-order sequence shows the fining upward or fining-coarsening upward cycle characteristic. Obvious onlap can be found above the SQ4 boundary in the seismic profile. (2)In the Shushanhe fember, the 3rd-order sequence boundary is mainly formed by the sedimentary transformation surfaces, which changes from lakeside or small delta sedimentary to a shallow lake sedimentary. This kind of 3rd-order sequence boundary is usually hard to be identified in the seismic profile.

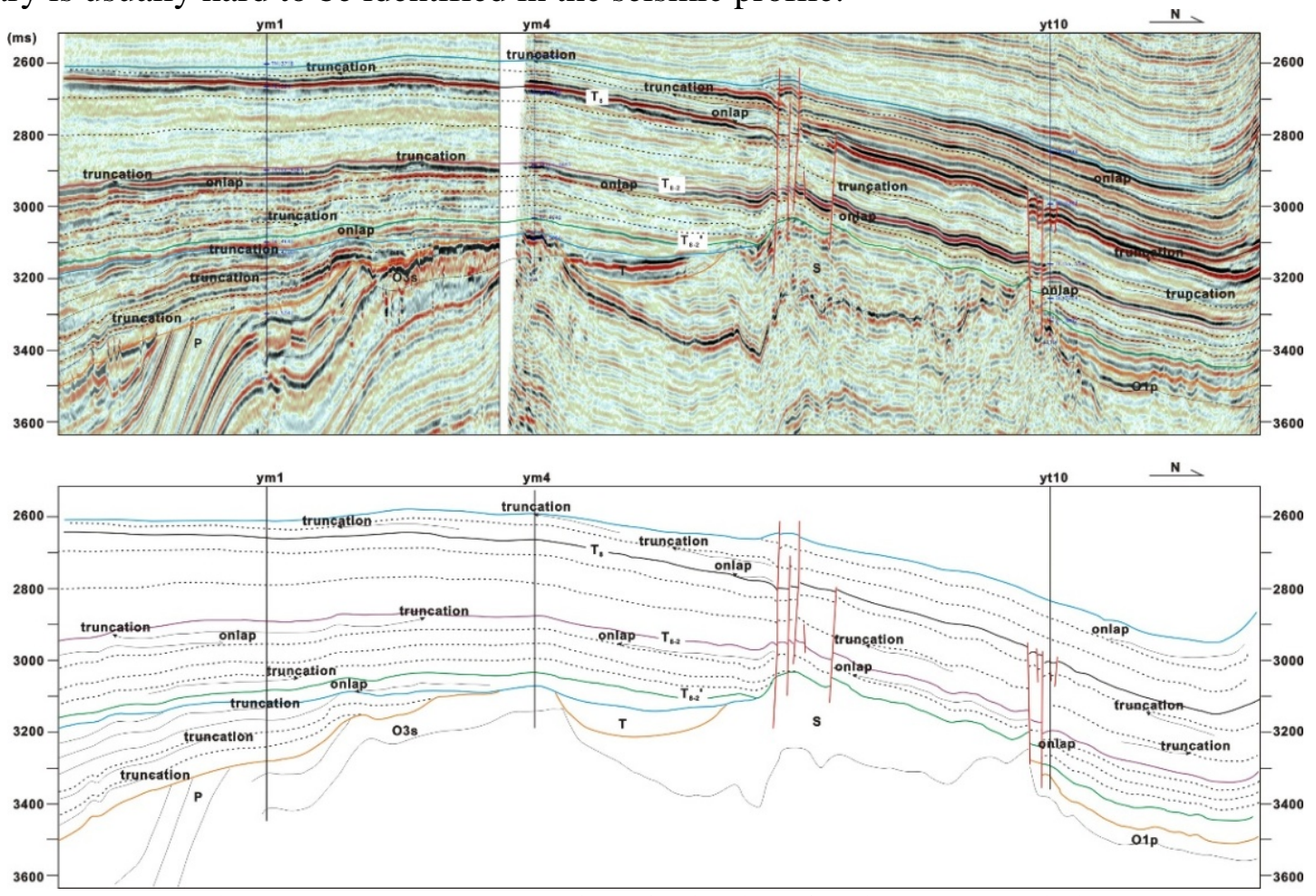

Figure3. Sequence boundaries of seismic reflection characteristics

\section{CREATION OF SEQUENCE STRATIGRAPHIC CORRELATION FRAMEWORK}

Through the calibration of synthetic seismogram in 20 wells and 6 wells in the VSP data, and the 
combination of well and seismic analysis, 12 skeleton profiles including 6 vertical profiles are chosen to undertake accurate comparison and analysis. On the basis of the above steps, sequence interfaces are compared and tracked in 3D space tracking, then, 3rd sequence stratigraphic frame of the Kapushaliang group has been created.

North-South seismic profiles accrossed from sag to Uplift and well profile (Figure 4) show sedimentary thickness of Kapushaliang group in three wells, named Ym1, S16, Ym4, at sag is respectively $384 \mathrm{~m}, 352 \mathrm{~m}, 307 \mathrm{~m}$, and great value. The underlying strata of Kapushaliang group are pebbled sandstone and rudaceous rock of Jurassic Yangxia Formation. The thickness of strata Uplift area has obviously become thin and ym16, ym462, ym30 layer thickness is respectively $168 \mathrm{~m}, 40 \mathrm{~m}$, $53 \mathrm{~m}$. The underlying strata of which is rhyolite porphyry, basalt and tuff of Permian.

With observing the sequence number, evolution and sedimentary thickness, 4 three order sequence can be identified at above three wells in sag; 2 three order sequence can be recognized at Ym16 well in slope; 1 three order sequence can be only distinguished at Ym424 and Ym30 well in Uplift. SQ1, SQ2 and SQ3 sequence from the direction of sag to uplift have gradually overlapped, thinned and disappeared. SQ4 sequence of each well was developed, but a thin thickness is occurred at the Uplift area. Research shows that three order sequences are developed in inside Kapushaliang group in the study area and the distribution of which are controlled by the palaeogeomorphology before the Cretaceous sedimentation. The southern part of the study area occurred remarkable thickness and complete strata, can be divided into 4 three order sequences. From the south to the north, at the bottom of the three order sequence towards the direction of Uplift show a gradual onlap. Because of slope has become steep, the sequence rapidly thin until thinning out and disappearance and 1 to 2 three sequence could be merely developed at high position of the Uplift.

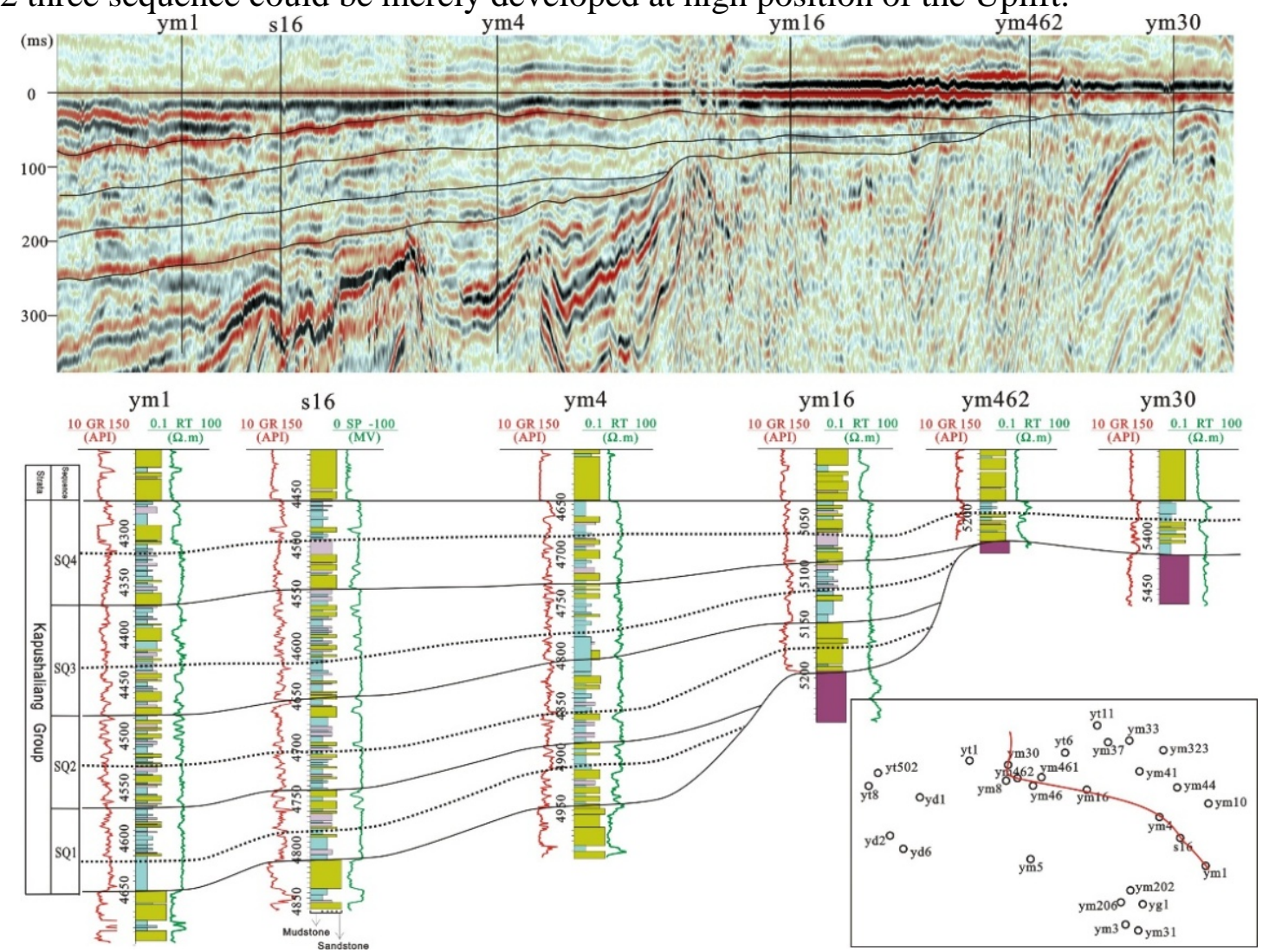

Figure4. Well -to-seismic matching of successions profile of Kapushaliang Group in North Tabei Uplift

\section{SEQUENCE DISTRIBUTION}

Based on the sequence division of single well and creation of frame profiles with the combination of well -to-seismic, careful comparison and trace have been carried out on the main sequence interface of Cretaceous in Tabei area. On the basis of above workflow, the major distribution characteristics of three order sequence can be confirmed explicitly in the study area. 
At the first sequence period, the Uplift was in erosional state .The stratigraphic overlap the Uplift. There were three depositional centers located at north and south side of the Uplift and well Yingmai-1 distinct. The strata at the south side of the Uplift are thicker than that at the north side. The thickness is up to $100 \mathrm{~m}$ or more. Sequence architecture at the well Yingmai-2 district, northern part of study area, obviously controlled by Uplift with a strike of north and south. Strata thickness is thinnest, less than $50 \mathrm{~m}$. Stratigraphic thickness contour strike coincides with the Uplift trend. The stratigraphic extended with an E-W trending. At the second sequence period, the strata at the north and south sides of the Uplift become into a continuous unit locally. The depositional center migrated to south part of study area. The maximum thickness is more than $100 \mathrm{~m}$. There are two depositional centers located at well Yingmai-5 and Yingmai-1 district. The strata thickness increased slightly around the Uplift, but much thinner than north part. Generally speaking, Stratigraphic thickness contour strike coincides with the Uplift trend. It reveals that sequence architecture obviously controlled by the Uplift. At the third sequence period, the erosional area became smaller, basically inherited the depositional pattern. The depositional center is still at the south part of study area. The strata thickness decrease from southeast to northwest.

At the fourth sequence period, the Uplift was covered by water and became depositional area. The depositional center still located at well Yingmai-1 district. The maximum thick is more than $110 \mathrm{~m}$. In addition there were two other depositional centers. The strata thickness near the well Yangta- 1 district is thinnest, only 40m.
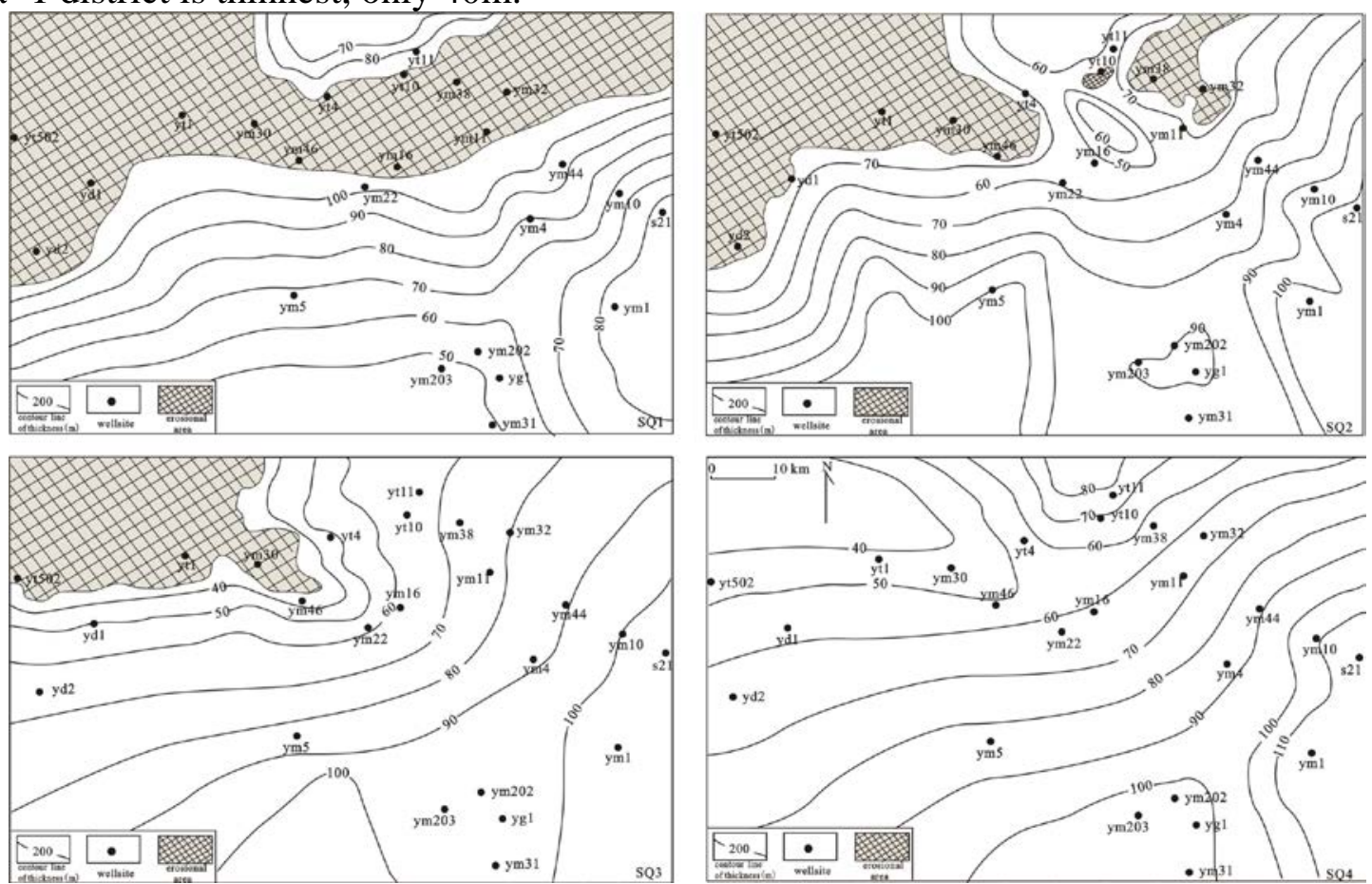

Figure5. Contour line map of the sequences thickness of Kapushaliang group in Tabei Uplift

\section{CONCLUSIONS}

(1) The Kapushaliang group of Tabei Uplift is a second- order T-R sequence that can be divided into four third-order sequences. Second- order sequence boundary performs as a large scale unconformity or a mutation in depositional environment. Third- order sequence boundary has two manifestations.

(2) 3rd-order sequence architecture obviously controlled by palaeogeomorphology. Sequence stratigraphic overlapped from sag to uplift layer by layer. The Uplift disappeared at the beginning of the fourth sequence. During that time, the strata at the north and south sides of the Uplift become into a continuous unit. There are four third-order sequences in the sag, while only one in the Uplift.

(3) The depositional center migrated in different stage of sequence architecture. The first sequence has three depositional centers located at north and south side of the Uplift and well Yingmai-1 distinct. The depositional center migrated to southeast and south part of study area in the 
last three sequences. During the second sequence, strata thickness slightly increased.

\section{REFERENCES}

1. An Haiting et al, 2009. Tectonic Evolution and Its Controlling on Oil and Gas Accumulation in the Northern Tarim Basin.Geotectonica et Metallogenia, 33(1) : 142-147 ( in Chinese with English abstract ) .

2. He Dengfa et al, 2008. Formation Mechanism and Tectonic Types of Intracratonic Paleo-Uplifts in the Tarim Basin.Earth Science Frontiers, 15(2): 207-221 (in Chinese with English abstract).

3. Li Guohui et al, 2007. Characteristics of Fault System in Yaha Structure Belt of Northern Uplift,Tarim Basin. Natural Gas Geoscience, 18(6): 859-863 (in Chinese with English abstract).

4. Sun Longde et al, 2002. Tectonics and Oil-Gas Distribution in the North Tarim Basin.Chinese Journal of Geology, 37(supplement): 1-13 (in Chinese with English abstract).

5. Sun Longde , Li Yuejun, 2004. The Lunnan Lower Uplift: A Multiple Oil-Gas Accumulation Play in the Tarim Basin. NW China, 39(2): 296-304 (in Chinese with English abstract).

6. Zhang Guanya et al, 1994. Deformation Style and Its Distribution in North Tarim Basin, Northwestern China.Earth Science-Journal of China University of Geoscience, 19(6): 755-768 ( in Chinese with English abstract ).

7. Zhou Fengying et al, 2001. Study on Direction, Phase and Pathways of Petroleum Migration in the Lunnan Area, Tarim Basin. Geological Review, 47(3): 329-335 ( in Chinese with English abstract ) . 